\title{
Sowing the seeds of an Indian fusion programme - an untold legacy of Vikram Sarabhai
}

\author{
Abhijit Sen* \\ Institute for Plasma Research, Bhat, Gandhinagar 382 428, India
}

THE year was 1970 and a faculty meeting was in progress in the committee room of the Physical Research Laboratory (PRL) in Ahmedabad. Among those present in the meeting was A. C. Das, then a young scientist who had joined the laboratory as a Research Associate just about a year ago. He was not yet a full faculty member but had nevertheless been asked by Vikram Sarabhai to attend all faculty meetings. He has a vivid recollection of how in the middle of that particular meeting Sarabhai had suddenly risen and gone to the blackboard to announce his plans for starting an experimental plasma physics programme in PRL that would act as a seed programme for a future fusion research programme in the country. He then briefly explained why it was important to do so not only for the present needs of the PRL but also for the future energy needs of the country. The announcement took everybody by surprise as PRL at that time was primarily engaged in space research, e.g. study of cosmic rays, ionospheric phenomena and some areas of basic theoretical physics. Das, who had done his doctoral work under the guidance of J. W. Dungey - the man whose seminal ideas had revolutionized our understanding of the earth's magnetosphere - had been hired for his expertise in magnetospheric physics and was expected to lend theoretical support to the experimental space programme at PRL. But Sarabhai saw beyond his usefulness to the space programme and recognized the value of his knowledge of plasma physics - so essential for the success of any fusion programme. As he sketched the outline of his plans on the blackboard, for which he also allocated a modest budget, it became clear that he had a clear strategy in mind for moving forward.

As always, finding the correct people was his first priority - something that he strongly believed in and had implemented for the space programme. So for some time now he had been systematically hunting for talent and hiring them. One of the first places he had looked for was the Tata Institute for Fundamental Research (TIFR), Bombay, where an earlier fusion-related experimental programme on a theta pinch had been unfortunately shut down and the group disbanded. The principal experimental scientists of that group had left and joined other areas of research. For example, Seetharam George, the leading scientist of that group had migrated towards development

*e-mail: abhijit@ipr.res.in of the microwave industry in the country that eventually led to the establishment of SAMEER (Society for Applied Microwave Electronics Engineering and Research). However, some of the eminent theorists were still around and Sarabhai was able to reach two of them. R. K. Varma, who had worked with Marshall Rosenbluth - one of the world leaders of fusion research and popularly acknowledged as the 'Pope' of plasma physics - had a strong background not only in fusion physics but also in fundamental plasma physics. He was one of the first persons to be recruited by Sarabhai. R. Pratap traced his lineage to the Brussels School of Ilya Prigogine and was an expert in formal statistical approaches to plasma kinetics and transport. He was also persuaded to join the fledgling PRL programme and was happy to do so.

The next catch was Bimla Buti - a former student of S. Chandrasekhar and at that time a faculty member at the Indian Institute of Technology Delhi (IITD) after her return from a two-year stint at the Goddard Space Flight Center (NASA), USA. Sarabhai had known about her and met her in Delhi at a dinner hosted for Chandrasekhar. They were seated on the same table and next to each other. As Buti recalls she was startled by the very first question that Sarabhai asked her - 'So Bimla, when are you joining PRL?' She did not know what to say and mumbled something about her willingness to come and give a talk but Sarabhai had other things in mind. He told her briefly about his plans for the plasma programme at PRL and invited her to join. Buti felt a bit cheeky at that point and asked him half-jokingly - 'How can you start such a programme without having a core group in place?'. To which apparently, Sarabhai had given his characteristic disarming smile and told her - 'Bimla, you say this because you do not know me!' Soon thereafter Buti received an invitation to visit PRL and give a talk followed by an offer to join the PRL faculty. It was when she had finally arrived in Ahmedabad did she realize how Sarabhai had been quietly busy creating a core group.

A. K. Sundaram - then a young scientist working at a NASA Centre in Hampton, Virginia - had sent a letter to Sarabhai enquiring about the possibility of employment in India. One fine morning he received an envelope from the Chairman, Dept of Atomic Energy, India. Inside was a letter from the personal secretary of the Chairman informing him that Sarabhai was in Washington, DC, for a meeting and would like to see him the following day during the lunch hour. Reaching the venue at the appointed time, Sundaram was ushered into an ante-room where he found Sarabhai having a quiet lunch. Sarabhai instantly got up and warmly welcomed him and asked him if he 
would like to join him in eating a 'khakhra' (a thin cracker snack) - which was what he was lunching on. This being his first meeting with the great man, Sundaram in his own words 'was totally awestruck and disarmed by the utter simplicity of the person in front of him'. Somewhat tongue-tied he tried to organize in his mind what he wanted to say. But before he could say anything, Sarabhai told him that he had gone through his application fully and was very impressed with his background and accomplishments. In particular he appreciated the fact that Sundaram was well versed in both fusion physics and space plasma-related research. He then briefly outlined the plans he had for the fusion cum plasma programme at PRL and why he felt it was important to launch such a programme. According to Sundaram, Sarabhai appeared to be well informed about the current status of fusion research in the world and particularly in the US - thanks perhaps to his strong academic connections with MIT. By the end of the meeting in addition to a 'khakhra', Sundaram also received a job offer to join the programme at PRL.

The next pick for the core group was a prize catch. Predhiman Kishen Kaw - the boy genius who had earned his Ph D from IITD at the age of eighteen and was currently dazzling his peers and seniors with his brilliance at the Princeton Plasma Physics Laboratory (PPPL) - the US flagship laboratory for fusion research. Predhiman's fame had obviously spread far and wide and Sarabhai was well aware of his prowess. He personally travelled to Princeton and sought him out and convinced him to return to India and join the nascent group at PRL. For him he spelt out his plans in greater detail and in the process struck a strong resonance with the young man's own desires and ambitions. Thereby he not only floated a dream in his mind but also lit a fire in his heart that had important consequences for the future.

Finally, the last member of the group! Soon after completing my Ph D in June 1970 I had come home and had gone to meet Sarabhai for his counsel and suggestions on my future plans. This was a natural thing for me to do as in a sense he had been my mentor from my undergraduate days. I had been fortunate to have been a member of a small pilot group that he had formed in the mid sixties to try out new science education methods based on the Physical Science Study Committee report that had come out in the US. The pilot study was the precursor to the establishment of the Community Science Centre - Sarabhai's unique contribution to science education for young children and society at large. The pilot group had continued to meet in PRL till our final undergraduate year with one of the PRL faculty members - K. B. Shah - exposing us to the Feynman lectures. Sarabhai would often stop by during our discussions and personally interact with us and question us on various topics. That early exposure to the research environment at PRL and the personal interest that Sarabhai took in us had inspired most of us towards a research career. When I went up to meet Sarabhai he seemed to know all about my graduate education and after congratulating me told me that he was very happy that I had done my dissertation in plasma physics. He then made me privy to his future plans for PRL and how he was building up a core team. At the end he told me 'I do not want you to go anywhere else but join us in this new venture'. To me this was a manna from heaven - to be able to work in my own special field in my home town and in the laboratory that I was so familiar with. Of course I instantly agreed but he made a condition. I was to go back to the US for a year and work in the fusion group at the Oak Ridge National Laboratory (close to my erstwhile graduate school) and pick up as much as possible about their experimental programme. He called S. R. Thakore to his office and instructed him to make all arrangements for my appointment in PRL and permission for me to spend a year away.

When after a year I came back and started work at PRL in mid-1971 the entire team was in place. The atmosphere was scintillating and it was an exciting time for all of us. While pursuing our own individual research problems we also spent a lot of time as a group planning for the future that Sarabhai had sketched out for us. One of the first items on the agenda was to initiate an experimental plasma programme that would set the ball rolling towards developing basic skills in plasma experimental techniques and also build up trained manpower. For the programme to have meaningful physics goals it was decided to align it with some of the major space plasma investigations of PRL. One of the first planned experiments was thus to create plasma conditions in a laboratory device that would permit exploration of instabilities associated with the $\mathrm{F}$ region and compare them to the in-situ measurements obtained from rocket borne instruments. Senior scientists from PRL like Satya Prakash who were engaged in such space experiments readily lent their support towards the planning of the laboratory experiments. To develop human resources for the future, large scale programme plans were drawn up to suitably augment the PRL graduate programme to train a large body of young talented students in theoretical and experimental plasma physics. For this the core group had sufficient expertise and experience to design a high level curriculum and to teach it. An active effort was also afoot to quickly acquire trained manpower to implement the planned experiments - partly by inducting fresh Ph Ds from within PRL and partly by recruitment of eminent faculty from Universities and other Institutions in India. The mood within the core group was very upbeat and for somebody like Kaw whose sights were set on the ultimate goal of setting up a fusion programme and who had the assurance of full support from Sarabhai, the level of excitement was quite palpable and visible to all around. His boundless energy and enthusiasm were also infectious and created quite a stir in the erstwhile sedate atmosphere of PRL. Above all, the vision of a clear path ahead forged a wonderful bond within the core group and provided a strong motivation to move forward.

Then we were all thunder struck on 30 December 1971 as the shattering news of Sarabhai's sudden demise in 
Kovalam reached us in PRL. For many of us who had known him personally it was a day of deep sorrow. His death was also a momentous loss for the scientific community in India as a whole and the fledging plasma group at PRL in particular. I remember Kaw recalling all the discussions he had had with Sarabhai in the recent past and the dreams they had shared. Fate seemed to have dealt a cruel blow. However the strength of his vision and the inspiration that he had provided helped us endure this catastrophic loss and move forward. Over the next few years the plans that had been put in place during Sarabhai's presence started unfolding under the energetic leadership of Kaw and with strong support from the new management at PRL. The enlarged graduate programme attracted a lot of young talent and the experimental programme took off well under the stewardship of P. I. John who had been a faculty member at Aligarh Muslim University and had been recruited to join the plasma core group at PRL. The effort was further strengthened by the contributions of scientists like Y. C. Saxena-who had just then obtained his $\mathrm{Ph} \mathrm{D}$ at PRL working on cosmic ray research in the Kolar Gold Fields - and S. K. Mattoo - who had done his $\mathrm{Ph} \mathrm{D}$ dissertation in the area of solar physics. Over the next few years the group saw tremendous progress in terms of both theoretical research and development of experimental expertise. Although the stated orientation was towards the simulation of space plasma phenomena, there was an unstated purpose of eventually acquiring the skills necessary for building fusion experiments. High vacuum, pulsed power, magnet design and fabrication were some of the skills acquired in this phase. Thus the foundation for a future fusion programme was rapidly being put in place.

However, the prospect of initiating such a programme seemed to be receding further and further. Times had changed and it was not easy to get government approval for such an ambitious programme amidst competing demands from other scientific projects and the overall budgetary constraints. Sarabhai's absence was keenly felt - he had departed far too early and without having had an opportunity to put the project on an official footing. The fast receding goal post led to considerable disappointment and disillusion among some in the group. Kaw decided to quit and to go back to PPPL in 1975. Some others went on sabbaticals to other institutions in the US and Europe. Many of the bright young graduates migrated abroad on postdoctoral or other long-term appointments. The fusion dream appeared to die.

But this is not the end of the story. The dream that Sarabhai had floated and the fires that he had lit in some of us did not die that quickly. The late 70 s saw a strong upsurge in fusion activities abroad particularly in the US. Tokamak machines world over were having a phenomenal success and the prospect of achieving controlled fusion suddenly appeared to be very bright. The enthusiasm within the fusion community was very contagious and inspired fresh hopes in many of us. It was felt that this was a right time to attempt a resurrection of the old dream and try initiating an appropriate programme in India. Plans were hatched during numerous discussions among Indian plasma physicists present in the US at that time and a proposal was finally sent to the authorities in India. It is a long story thereafter and needs a separate telling but the end result - thanks to strong support from people like Devendra Lal, S. P. Pandya and M. G. K. Menon - an independent programme supported by the Dept of Science and Technology, named Plasma Physics Programme (PPP), was launched in PRL in 1982. The programme centred around a Tokamak device - ADITYA - drew on the existing experimental expertise at PRL and was expected to attract many of the Indian plasma physicists who had migrated abroad. Kaw returned to India and assumed directorship of the programme in the same year.

The rest is history, as they say. That initial 'nucleation' at PRL - a favourite ploy of Sarabhai who had launched many an ISRO programme in that manner-has today given rise to the Institute for Plasma Research with a thriving programme in fusion research and many allied areas of plasma physics and plasma technology. India is an equal partner in the largest international fusion programme - the International Tokamak Experimental Reactor (ITER) - and is contributing actively to the world fusion research effort. The dream has now materialized and put us on the path to exploiting this future source of abundant energy. It has taken a long time to realize this dream since it was first spelt out in the committee room in PRL and many players have contributed to bring this about. The early history - the beginnings of the journey is now buried in the past and mostly forgotten. However, it embodies another important legacy of Sarabhai that has remained overshadowed by his other well-known achievements and is worth recalling in this year of celebrating his hundredth birth anniversary. It is a legacy that highlights once more the breadth of his scientific awareness and his remarkable vision for the future of the country. That he conceived of a fusion programme way back in 1970 and did the initial spade work for it also makes one wonder about what course we would have taken had he lived longer. Could we have leap frogged much further with such an early start? Recalling the long period it took after his death to revive the programme and maintain the enthusiasm and stamina for doing so, one must perforce acknowledge and be grateful for the valuable legacy he had bequeathed us and the head start he had given us. One hopes that this legacy will continue to inspire the present and future generations of fusion researchers in India and lead to the fulfilment of that grand vision and the realization of the ultimate goal of achieving fusion power for the country.

ACKNOWLEDGEMENT. I am grateful to many members of the original core group for sharing their memories of that early period with me and to P. I. John for a critical reading of the manuscript and very helpful suggestions.

doi: $10.18520 / \mathrm{cs} / \mathrm{v} 118 / \mathrm{i} / 1196-1198$ 